\title{
FOOD WASTAGE AND IMPLICATIONS FOR FOOD SAFETY WITH SPECIAL REFERENCE TO MARRIAGE CEREMONIES
}

\author{
Waseem Akram*, Iqbal Javed \\ Department of Economics, The University of Lahore, Sargodha Campus.
}

ARTICLE INFO

\section{Article History}

Received: January 15, 2021

Revised: March 14, 2021

Accepted: August 25, 2021

\section{Keywords}

Food safety

Food wastage

Quantity

Behaviour

Awareness
A B S T R A C T

This study estimates the quantity of food waste and its causes in the marriage ceremonies in district Sargodha, Pakistan. A questionnaire was prepared for the collection of data on food waste. Before final data collection, a pilot survey was conducted and some changes have been made as per suggestions of the stakeholders. Every marquee and marriage hall were visited several times for data collection and data about 255 events of marriage ceremonies was collected. Along with empirical data, the focus group discussions and interviews were organized with managers and the staff of the marriage halls and marquees. Their experience and views were also recorded for the theoretical understanding of the science of food waste and its causes. The study concludes that, on average, every individual waste 183 grams of food in a marriage ceremony in district Sargodha. From theoretical side, it is concluded that guest's unawareness about food waste and the typical behaviour of the guests are the major reasons of food waste in marriage ceremonies. While on the empirical side, the major reason of food waste is the buffet serving that causes to increase the quantity of food waste very significantly.

Corresponding Author: Waseem Akram

Email:cwa555@gmail.com

(C) The Author(s) 2021.

\section{INTRODUCTION}

Wastage of food is continuously increasing globally and by 2050 it will become more than double of the current food waste. The increasing demand of food worldwide also putting pressure on agricultural output, forcing farmers to increase the area of agricultural land or use genetic modifications to increase per capita output (Hiç et al., 2016). Along with major challenges of global warming and climate change, world may face food shortages in years to come. This situation directs us to divert our attention towards the issue of food waste. If waste issues remain unsolved, humans will face a severe crises of food shortages in the future.

In 2011, Food and Agriculture Organization (FAO) published its first report regarding food losses and food waste. The FAO also distinguished first time between the terms, food losses and food waste. Food loss was referred as decrease in quality or nutritional value of food that was initially projected for human consumption. The food losses can be driven by inefficiencies in supply chain i.e. poor infrastructure for food processing, lack of technology, limited access to market, insufficient knowledge and management capacities. Food waste was referred as the disposal of appropriate food that is available for human consumption, no matter if it was kept beyond its expiry date or was left to spoil (FAO, 2011).

Food and Agriculture Organization (2015) reports that around 800 million people are unable to afford sufficient food globally and the biggest risk to human health is 
hunger and malnutrition. Cumulatively, 3.1 million children die every year due to undernourishment (Black et al., 2013). In other words, 1.3 million tons of food gets wasted without any human consumption (FAO, 2011). The developing world alone wasted food of worth US $\$ 310$ billion (Aamir et al., 2018).

In the last decade, food waste has received attention of policy makers due to its negative impacts on the wastage of resources, environmental pollution and social development (Cuéllar and Webber, 2010; Godfray et al., 2010; Gustavsson, 2011; Kummu et al., 2012). Number of researches have been undertaken to measure the quantity of food waste due to irresponsible behavior of society. In developed countries, major portion of food gets wasted at consumption stage while in developing countries, a significant amount of food also gets wasted throughout the supply chain. Food gets wasted at consumption stage attracts particular attention because large amount of food waste means all the resources and inputs at production, processing, storage and distribution stage was used in vain and all this occurs at the expense of Green House Gas (GHS) emissions and environmental pollution due to wastage (Vittuari et al., 2016). The households contribute major share of food waste that accounts for $53 \%$ of the total food waste. The share of manufacturers in the waste is $30 \%$ percent during production and processing while retailers and food service contributes $5 \%$ and $12 \%$ respectively (Block et al., 2016). According to Searchinger et al. (2019) Europe alone contributes 22\% percent of the global food waste. Rapid increase in global population and decrease in per person availability of resources and energy for the production of food further intensifies the problem of food waste and creates issues of food shortage and malnourishment (Pimentel \& Pimentel, 2008). Many studies have been undertaken on food waste at consumption stage taking it as aggregate sector (Cuéllar and Webber, 2010; Gustavsson, 2011; Kummu et al., 2012) but do not have a focus on different segments within the consumption sector.

\section{The Definition of Food Surplus}

When we refer to food waste or food surplus, we often get confused with other related proper nouns. Food surplus or food waste have different definitions when considering different aspects. Papargyropoulou et al. (2014) stated that in the literature on food surplus management in various countries, the definition of food surplus was not unified; therefore, it was difficult for us to compare such research results in a systematic manner. When the terms in research are not expressly defined and target items are unclear, it is timeconsuming and difficult to conduct a relevant analytic comparison. When we can clearly classify food into specific categories, it is easier to analyze food waste from the aspect of improvement controls. Common terms relating to food waste and food surplus are food surplus, food loss, and food waste, as described below.

(1) Food surplus: Due to the overproduction of food in agricultural production processes, excessive amounts of agricultural products imported by a government, weather effects, and market prices impacting farmers' decisions in terms of crop choice, there is a post-harvest oversupply, and uneaten vegetables and fruits are discarded before arriving at suppliers, food processing plants, restaurants, and consumers (Papargyropoulou et al., 2014).

(2) Food waste: Food waste occurs at the end of the food supply chain (retail and consumption), as restaurants misestimate the purchase quantity, which causes food spoilage; retailers purchase excessive amounts of vegetables and fruits for promotions; oversized meals are prepared; "best before" dates and validity periods mislead the public to believe that food is inedible after the specified dates; and snack stands make excessive food and place it on shelves to attract customers, but discard such food when it does not sell. Such food waste refers to discarding food that is still edible; therefore, the term "food waste" is a form of intentional discarding behavior (FAO, 2011).

(3) Food loss: Food loss generally refers to any food that is wasted during post-harvest processing or transportation of agricultural products at an early stage of the food supply chain; food that cannot be sold due to pest infestations, shape, improper storage during transportation, and so forth; and food materials being trimmed in order to form them into another shape to meet the standard for production-related reasons. Removal of edible parts for consistency of products is classified as unintentional food waste (FAO, 2011).

\section{Statement of the Problem}

A significant quantity of food gets wasted in the marriage ceremonies. On one side, the wastage of edible food is the wastage of resources that were used in the production and processing of that food. On the other side, the disposed quantity of wasted food creates environmental issues by emitting methane that is very 
dangerous for organisms. The aim of the study is to identify the quantity of food waste in marriage ceremonies in district Sargodha and its causes.

\section{Significance of the Study}

According to Farooqi et al. (2016) on average, a person wastes 475 grams of food in a marriage ceremony. This waste of food is more than the quantity of food that an average person consumes per meal at home. Cumulatively, 26.81 million tons of food gets wasted in Muslim marriage ceremonies. This wasted quantity of food is enough to feed 20.53 million people with three meals per day. By avoiding this waste, we can save enough food that the entire population of Somalia and Haiti can be fed. So, addressing the issue of food waste in marriage ceremonies is of vital importance.

\section{REVIEW OF LITERATURE}

Food waste is a complex phenomenon and reasons of food waste are multi-dimensional. The behavior of food consumers plays important role in determining the quantity of food waste. In addition to that food-related practices also play important role in increasing the quantity of food waste. In this chapter, we have reviewed different studies conducted on role of human behavior in determining food waste and the role of household food practices on the quantity of food waste.

\section{Food Waste and Human Behavior}

The production and consumption of food sets severe environmental effects, particularly in case of food waste. (Janssens et al., 2019) studied the role of consumer behaviour related to food provisioning in wasting food. Food got wasted over the entire food chain system but major share of food is wasted by households. This study conducted a survey among Dutch consumers. A total of 211 consumers participated in the survey and answered the questions related to household composition, food management behaviour and food waste awareness. The findings of the study confirmed that the purchase behaviour plays the main role in food waste. The participants explained that buying more than needed food more often led to food waste. Age of consumers has been found a diminishing factor of food waste.

(Graham-Rowe et al., 2014) worked to identify the motivations and barriers to minimize food waste in the UK. The study reports the thoughts, feelings and experience of 15 UK household food purchasers, based on semi-structured interviews. The study successfully identified two core motives to minimize food waste: (1) waste concern and (2) doing the right thing. Food management skill also empower the people to keep the food waste at minimum. The following barriers to minimize the food waste were identified: (1) the "good" provider ability. The study identified that desire not to waste good food was a significant motivation, so was the desire to be a "good" parent, "good" partner or "good" host. The need to feel like a "good" provider was fulfilled by over-purchasing of food and it was considered as significant barrier to minimize food waste. The other barriers to the attempts to minimize food waste include (2) minimizing inconvenience, (3) lack of priority and (4) exemption from responsibility. The efforts to avoid experiencing negative emotions (such as guilt, embarrassment or regret) underpinned both the motivations and barriers to minimizing food waste. The study found conflicting personal goals that may hamper existing food waste reduction attempts.

The increasing awareness about food waste has positive effects on environment especially on greenhouse gas emissions, energy use, food and water security, and land use. In developed countries, major share of food waste comes from household consumption. The behaviour attached with food waste is very complex for number of reasons. Food waste is the result of multiple interactive activities that leads to the separation between activities and their consequences. People perform certain behaviours for different reasons that are unrelated with food waste reduction and marked as habitual element and emotional component. Furthermore, avoiding food waste has less "visibility" for other (e.g. neighbours or other members of the society) than the other proenvironmental activities that are more visible and provide emotional boost. So, food waste reduction as social norm plays less role as compared to other more "visible" activities. Quested et al. (2013) studied insights into these behaviours of food waste. It has been discussed that how these insights have been used in the development of a successful public engagement that has played a critical role in reducing food waste at household level.

\section{Quantity of Food Waste and Effects of Waste Reduction Measures}

Farooqi et al. (2016) studied the causes of food waste in Muslim marriage ceremonies in case of mega city of Karachi. The study estimated that, on average, a person wastes 475 grams of food in marriages that is more the than the average quantity consumed per meal at home. 
The study projected that cumulatively 26.81 million tons food is wasted in the marriage ceremonies of the Muslims. This wasted quantity of food is enough to feed 92.40 million people with two meals per day. Mainly, the identified causes of food waste are: very late serving, inappropriate food combination, guest's perception about food shortage, large per unit food portions and scrambling around food tables. The study revealed that food inadequacies and consumption behavior are the causes of inefficiencies in the food consumption behavior.

Mabaso and Hewson (2018) studied current food waste practices and employees' perception about food waste in hotels of Gauteng, South Africa. Relevant stakeholders in food waste generation were interviewed using a structured questionnaire. The results revealed that the concerned staff generally had a positive perception about environmental issues pertaining to food waste generation. Strotmann et al. (2017) studied the effects of measures taken against food waste on the waste quantity in three healthcare food service facilities. Quantities of food produced and wasted were measured initially. Through participatory approach, employees were integrated to develop and implement the food waste reduction measures. After the implantation of waste reduction measures, the quantities of food produced and wasted were again measured. The results showed a significant reduction in the waste from 21.4 percent to 13.4 percent in residential area and 19.8 percent to 12.8 percent in the cafeteria of the hospital.

Falasconi et al. (2015) investigated the food losses and waste in the catering services of six schools located in Verona, Italy. The study measured the quantity of food waste as food catering inefficiency, identified the causes and suggested some waste reduction interventions. They found serious inefficiencies in food catering services, measured by the amount of food processed and edible but not served as a meal. The results revealed that 15 percent of the processed food was wasted. The identified causes were lack of attention to dietary habits, the rigid food procurement specifications, the menu composition and the meal presentation. Food waste in school cafeteria is significant and represent an excellent opportunity for diverting food waste from landfills. Wilkie et al. (2015) measured food waste in the three Florida schools. Food waste comprised the largest share of school cafeteria waste ranging from 47 percent to 58 percent more than milk, paper and plastic waste. Among three schools, the average quantity of food waste is $\mathbf{5 2 . 2}$ grams per student per day. The study suggested two approaches to divert food waste from landfills: reduction and recycling. Food waste can be reduced by educating students and staff in order to change their behavior regarding food waste. The wasted food can be collected and recycled through composting or anaerobic digestion. More than 75 percent of the café waste measured in this study can be recycled.

Schanes et al. (2018) thoroughly reviewed the empirical studies conducted on food waste and also studied the factors that foster or impede the generation of food waste at household level. Based on the review of 60 peer-reviewed articles, the study found that food waste is complex and multi-faceted issue that cannot be attributed to a single variable. The behavior of households toward food waste and food-related household practices both have their role in the generation of food waste.

\section{Theoretical Background}

The behaviour of an individual is considered as critical in determining the amount of food waste (Schanes et al., 2016). In Italian consumers, Bravi et al. (2019) found three behavioral antecedents for food waste i.e. over preparation, excessive purchase and inappropriate conservation. Avoiding food waste mainly depend on consumers e.g. regarding conserving food in appropriate manner, however, retailers can also play a role regarding purchase behavior of consumers through avoiding excessive purchasing (Janssens et al., 2019). Different varieties of food products and their availability in larger quantity leads to higher food waste. More replenished supplies increase the likelihood of different food products to run past their sell-by date and wasted (Calvo-Porral et al., 2016). A study by Janssen et al. (2017) in Dutch context found significantly lower amount of food waste when households use frozen food instead of fresh food. Much of the amount of food waste is related to the behavior of consumers and households.

Theory of planned behavior is referred in the literature as a potential explanation for the behavior of consumers towards food waste. According to the theory of planned behavior an individual performs specific behavior due to behavioral intensions of willing to behave in a certain way (Ajzen, 1991). It states that the behavior can be explained through the intensions that a person has to actually show that behavior. As it is believed that consumers are waste aversive and it is the intentional 
processes that drives their behavior toward food waste (Bolton \& Alba, 2012). Actually, consumers perceive food waste as food related behavior as compared to a problem for environment or society and are not yet fully aware of the environmental and social impacts of this waste (Graham-Rowe et al., 2014; Quested et al., 2013; Quested et al., 2011; Thyberg and Tonjes, 2016).

Food products went through different journeys like planning, shopping, storage, preparation and consumption. Food waste depends on how households deal with these different stages. For instance, shopping without making a list may result in buying a food that is already in the fridge, which subsequently may result in failure to consume food before the expiry date (Janssens et al., 2019). Alternatively, lack of planning for the consumption of food already available with the household may result to run past its expiry date. In any case, food gets wasted due to storing it for too long and when food is thrown away, the opportunity to prevent food waste is lost (Quested et al., 2013; Roodhuyzen et al., 2017).

In Muslim countries like Pakistan, a lot of food gets wasted in a dinner or lunch that is offered to the invited guests as a compulsory part of each marriage ceremony. (Farooqi et al., 2016) studied that, on average in a mega city of Karachi, a person wastes 475 grams food in a dinner or lunch that is offered on the occasion of marriage. The study projected that 26.81 million tons of food gets wasted worldwide in Muslim marriage ceremonies. The authors identified different reasons for such a high food waste e.g. late serving of meal during marriage ceremonies, the perception of guest's about shortage of food, larger quantity of cooked food per person, buffet serving, and inappropriate food combination (Farooqi et al., 2016).

This study aims to identify the quantity of food waste in marriage ceremonies in district Sargodha, Punjab, Pakistan. In addition, the study also tries to identify the reasons of food waste and its management in case Muslim marriage ceremonies.

\section{METHODOLOGY}

As part of Sub-continent, Pakistan has a history of traditions to organize large scale feast on the occasion of marriages. In these events, a large number of people including relatives and friends are invited for celebrations where they are served with large and diversified meals. In these gatherings a lot of food is wasted.

Food waste in marriage ceremonies can be of two types, for example, food left in the serving dishes and leftover food in the plates. The first type of food waste can be used by different segments of the society including the workers involved in food serving at marriage halls and marquees. The plate waste is normally disposed of and this amount of food waste has environmental effects for the society. This study has measured the quantity and identified the reasons of second type of food waste (plate waste).

As very few studies have been done on the issue of food waste in marriage ceremonies in Pakistan. Therefore, many people from the food industry including managers and staff in marriage halls and marquees were interviewed and focus group discussions had been organized with the stakeholders on this issue.

A questionnaire was prepared for the collection of data on food waste. Before final data collection, a pilot survey was conducted and some changes had been made as per suggestions of the stakeholders.

\section{Sampling Plan and Data Collection}

For sampling purpose, first of all, the president of the Association of Marriage Halls and Marquees Sargodha was approached to get the data of all the halls and marquees situated in district Sargodha. The list of all the marriage halls and marquees was obtained from the Association office. There were 74 marriage halls and marquees in the list that were registered with the Association. For data collection, marriage halls and marquees were visited to brief them about the nature of study and also to get the schedule of booked events of marriage ceremonies. Several owners were reluctant to cooperate and were not ready to give the data. But after the assurance of the fact that the collected data will be used for only research purpose, they also agreed to cooperate.

Every marquee and marriage hall were visited several times for data collection and data about 255 events of marriage ceremonies was collected. Out of 74 marriage halls and marquees, every hall was visited three to four times to avoid biasedness and a sample of 255 was collected for the analysis. The following procedure was adopted for data collection and to monitor the characteristics of the family for whom the hall or marquee was booked, on the day of event.

The principal investigator and other enumerators along with research assistant reached before the start of the 
event. One enumerator was assigned to observe the guests and collect overall information about the gathering like culture, habits and background. The situation at the time when food was placed on the tables and was ready to serve, was closely observed. As highlighted in the earlier study by Farooqi et al. (2016) that late serving also causes to increase the quantity of food waste, so the difference in the time for serving food mentioned on the invitation card and in the time when food was actually served was noted. After that, habits and behaviour of eaters towards food was closely observed to determine the reasons of food waste. In the end, the total food waste was collected and weighted. In addition to that, randomly selected persons from the guests were interviewed and were asked different questions about food waste to judge the understanding and behaviour of the participants regarding food waste. The focus group discussions and interviews were organized with managers and the staff of the marriage halls and marquees. Their experience and views were also recorded for the theoretical understanding of the science of food waste and its management. The following things were observed indirectly or asked directly during the whole process of data collection.

An enumerator was deployed to record the background of the host family and their invited guests. For that purpose, he used different methods and indicators like the area from where the host family belongs, through physically observing the invited guests, the way of interaction of the guests with each other and through observing the eating manners of the invited guests. The opinion of the hall manager was also recorded in this regard e.g. what he thinks about the family based on his experience. From the combination of all of these methods, each family was categorized as rural or urban.

Financial soundness of the host family was established as financially weak, financially stable or financially strong family. For this, the study used per head cost of the meal served, the apparent look of the invited guests, number of dishes in the menu and type of meat to decide about the financial condition of the host family. Details about the number of invited guests were recorded as per the information provided by the hall manager. The mode of serving meal was also noted whether it was served on the tables or as buffet.

In the end, the total quantity of wasted food was measured on the weight machine and recorded. A question regarding the method of the disposal of wasted food was asked from the marriage hall administration. The hall manager and staff were also asked following questions: Do you think on-table serving considerably reduce the food waste? Do you think guest's unawareness regarding food waste is a cause of food wastage? Do you think inappropriate food combination is a cause of food wastage? Do you think scrambling around food tables is a cause of food wastage?

\section{RESULTS AND DISCUSSION}

\section{Focus Group Discussions and Interviews}

In the discussion with the managers and hall staff, it is found that there are many reasons of food waste in the marriage ceremonies and each reason contributes separately in the total quantity of food waste. It is established on the basis of whole discussions that the major reason of food waste is the typical human behaviour of the people towards food. The wish of eating more pushed the people to take more quantity of food in their plates. And when they start eating, they realized that they would not be able to eat the whole quantity of the taken food and the food remains uneaten in the plate.

Most of the participants who were interviewed explained that the buffet serving causes to increase the food waste. When it was asked that when you know that the buffet causes relatively more food waste, why food is being served in buffet settings. Majority replied that it depends on the requirements of the host family, some families objectively demand for buffet serving. Some of them justified buffet servings in a way that in on-table serving greater quantity of food is consumed by the guests as compared to the food consumed in the buffet serving. So, it suits to the hall administration to serve in buffet settings.

The managers and hall staff were asked to respond on the question "Do you think guest's unawareness regarding food waste is a cause of food wastage?" Most of the participants reported that the awareness about food waste plays an important role in the reduction of food waste. Several of them also quoted the examples about the events where food waste was negligible and they consider that this was due to the awareness of the invited guests towards food waste. Majority considers that unawareness about food waste is a cause of food waste in the marriage ceremonies. The managers and hall staff were also asked to respond on these questions: "Do you think inappropriate food combination is a cause 
of food wastage", and "do you think scrambling around food tables is a cause of food wastage". They were of the view that inappropriate food combination is just a minor cause of food waste while, sometime, scrambling around food table causes to increase food waste significantly in marriage ceremonies.

The discussion with the stakeholders concludes that they believe a certain ratio of food quantity gets wasted in every case and we cannot avoid it. They were of the view that approximately 30 to $40 \mathrm{~kg}$ of food gets wasted in an event where 100 people are invited for the meal. They were under strong believe that this quantity of food waste is very difficult to reduce because of the typical thinking of invited guests that as it has been paid for the meal and everything else so they have every right to behave cruelly.

The guests invited in the marriage ceremonies were also interviewed. When a guest was asked about whether he knows that on average every invited guest including himself wasted more than 400 grams of food apart from eating as per the study by Farooqi et al. (2016). Most of them were unaware about such a high quantity of food waste and were shocked to listen about it. It was also observed that in some events where and when participants were aware about the problem of food waste and its importance, in those cases, food waste was considerably less as compared to other events.

The method of disposal of food waste was almost same for all the marriage halls and marquees. All the marriages halls and marquees were throwing the wasted food in some open place away from their marriage halls or marquees.

\section{Empirical Results}

Table 1 presents the results of food waste categorized by family background, type of serving, type of dishes. The quantity of per-person food waste among rural families is 195 grams, while among urban families this quantity is 165 grams. So, on average, in the events related to rural families, 30 grams per person more food is wasted as compare to urban families. The significance of this difference has been checked by apply t-test for paired samples. P-value of the test clearly indicates that the difference in the waste of rural and urban family is statistically significant.

Table 1. Quantity of food waste by different categories.

\begin{tabular}{|c|c|c|c|c|c|c|}
\hline \multirow{2}{*}{$\begin{array}{l}\text { Per-person food waste } \\
\text { categorized by family } \\
\text { background (in grams) }\end{array}$} & Rural family & Urban family & Difference & T-value & \multicolumn{2}{|c|}{ P-value } \\
\hline & 195 & 165 & 30 & 4.60 & \multicolumn{2}{|c|}{0.000} \\
\hline \multirow{2}{*}{$\begin{array}{l}\text { Per-person food waste } \\
\text { categorized by type of } \\
\text { serving (in grams) }\end{array}$} & Buffet & $\begin{array}{c}\text { On-table } \\
\text { serving }\end{array}$ & Difference & t-value & \multicolumn{2}{|c|}{$\mathrm{p}$-value } \\
\hline & 207 & 136 & 71 & 12.75 & \multicolumn{2}{|c|}{0.000} \\
\hline \multirow{2}{*}{$\begin{array}{l}\text { Per-person food waste } \\
\text { categorized by type of } \\
\text { dishes (in grams) }\end{array}$} & Beef & Chicken & Mutton & $\begin{array}{c}\text { Difference } \\
\text { (Chicken- } \\
\text { Mutton) } \\
\end{array}$ & t-value & $\mathrm{p}$-value \\
\hline & 173 & 197 & 143 & 54 & 5.65 & 0.000 \\
\hline
\end{tabular}

The per-person food waste in buffet serving is significantly higher than the on-table serving. In events with buffet serving the average food waste per-person is 207 grams while in feasts with on-table serving it is 136 grams per-person. Almost 71 grams per person more food is wasted in the events with buffet serving as compare to the events with on-table serving. The meandifference t-test indicates the difference is statistically significant. When events are classified with the type of meat served, the average food waste per-person is 173 grams in events where beef was served to the guests. While events served with chicken have 197 grams average waste per person and the events in which mutton was served have, on average, 143 grams food waste per person. When compared with the waste of chicken with mutton, it is $\mathbf{5 4}$ grams per person more in chicken case. The statistical significance of the difference between mutton and chicken waste has been checked with t-test. P-value shows that the difference is statistically significant. 
Table 2. Quantity of food waste by different categories.

\begin{tabular}{lcc}
\hline \multicolumn{3}{c}{ Food Waste categorized by number of guests (in Kilograms) } \\
\hline No. of Guests & Total waste (kilograms) & Per person waste (grams) \\
\hline $0-100$ & 26.400 & 264 \\
$101-200$ & 50.200 & 251 \\
$201-300$ & 63.933 & 213 \\
$301-400$ & 72.567 & 181 \\
$401-500$ & 81.178 & 162 \\
$501-600$ & 93.433 & 156 \\
$601-700$ & 110.767 & 158 \\
$701-1000$ & 165.300 & 165 \\
\hline
\end{tabular}

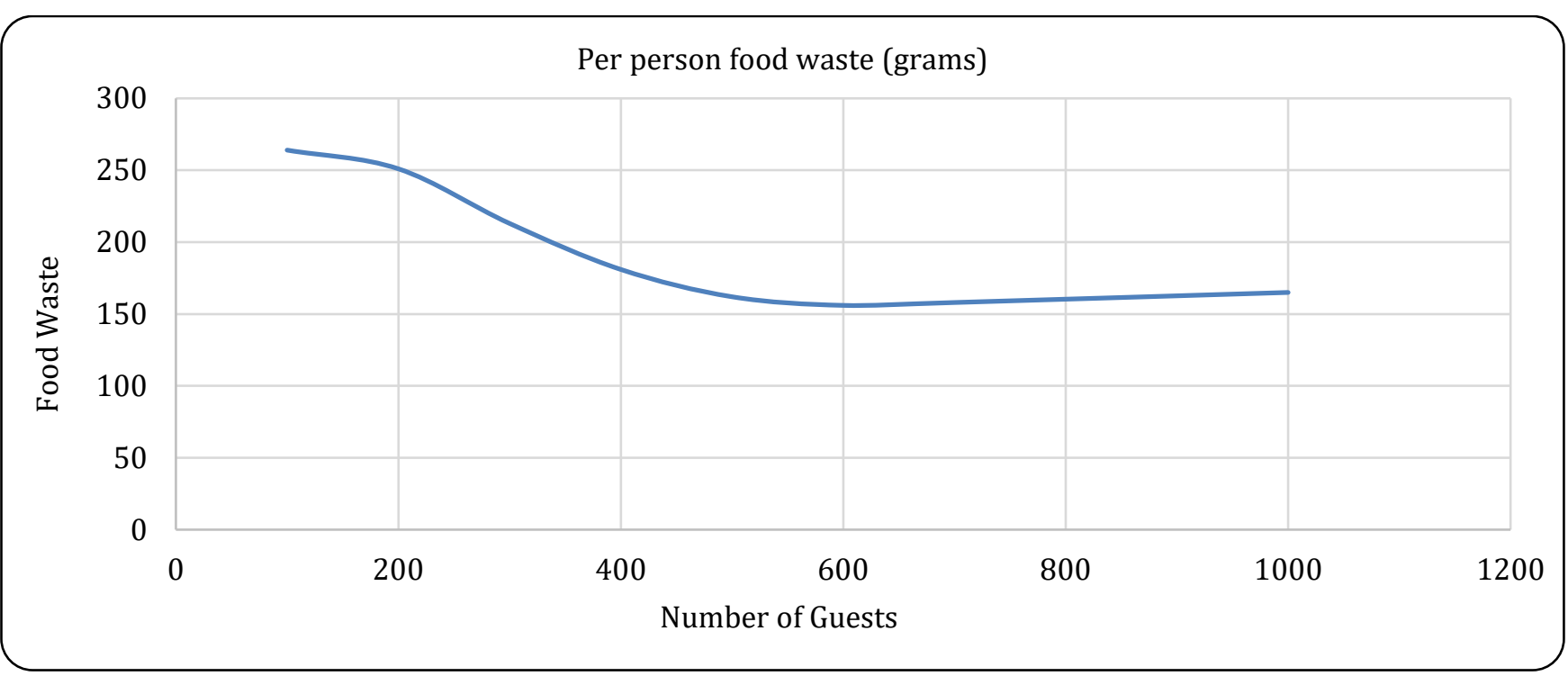

Figure 1. Trend in per person food waste with the increase in number of guests.

Table 2 shows the results of food waste categorized by number of guests. The classification of events according to number of invited guests shows that the events with up to 100 guests have, on average, 26.400 kilograms of total food waste. The average waste in the event with more than 100 to 200 guests have 50.200 kilograms. The quantity of average waste in the events with guests 201-300, 301-400, 401-500, 501-600 and 601700 is $63.933,72.567,81.178,93.433$ and 110.767 kilograms respectively. The average waste in the event with more than 700 to 1000 guests is 165.300 kilograms. As shown in figure 1, it is important to note that the per person food waste decreases as number of guests increases. The per person food waste is around 260 grams for the events with up to 100 guests while it reduces to around 160 grams for the events with guests up to 700 or more.
Table 3 provides the quantity of food waste for rural and urban families classified according to the number of invited guests in the event. It is clear from the results that average waste in the events that belong to rural families is higher than the events belong to urban families. The quantity of average food waste is higher for rural families. The rural-urban family's food waste difference is high for higher number of invited guest's events as compare to the smaller number of invited guest's events. The highest rural-urban family's food waste difference is for the slab 601-700 while the lowest rural-urban family's food waste difference is for the slab 101-200. Figure 2 clearly shows that the food waste has increasing trend with the increase in the number of invited guests. The rural-urban family's food waste difference also has a slight increasing trend with the increase in the number of invited guests. 
Table 3. Cross tabulation of number of guests and family background (kilograms).

\begin{tabular}{lccc}
\hline No. of Guests & Rural family & Urban family & Difference \\
\hline $0-100$ & 29.900 & 19.400 & 10.500 \\
$101-200$ & 51.444 & 48.333 & 3.111 \\
$201-300$ & 66.000 & 60.833 & 5.167 \\
$301-400$ & 74.390 & 68.632 & 5.758 \\
$401-500$ & 88.125 & 73.238 & 14.887 \\
$501-600$ & 100.813 & 85.000 & 15.813 \\
$601-700$ & 120.529 & 98.000 & 22.529 \\
$701-1000$ & 171.294 & 157.462 & 13.832 \\
\hline
\end{tabular}

Source: Author's estimation from survey data

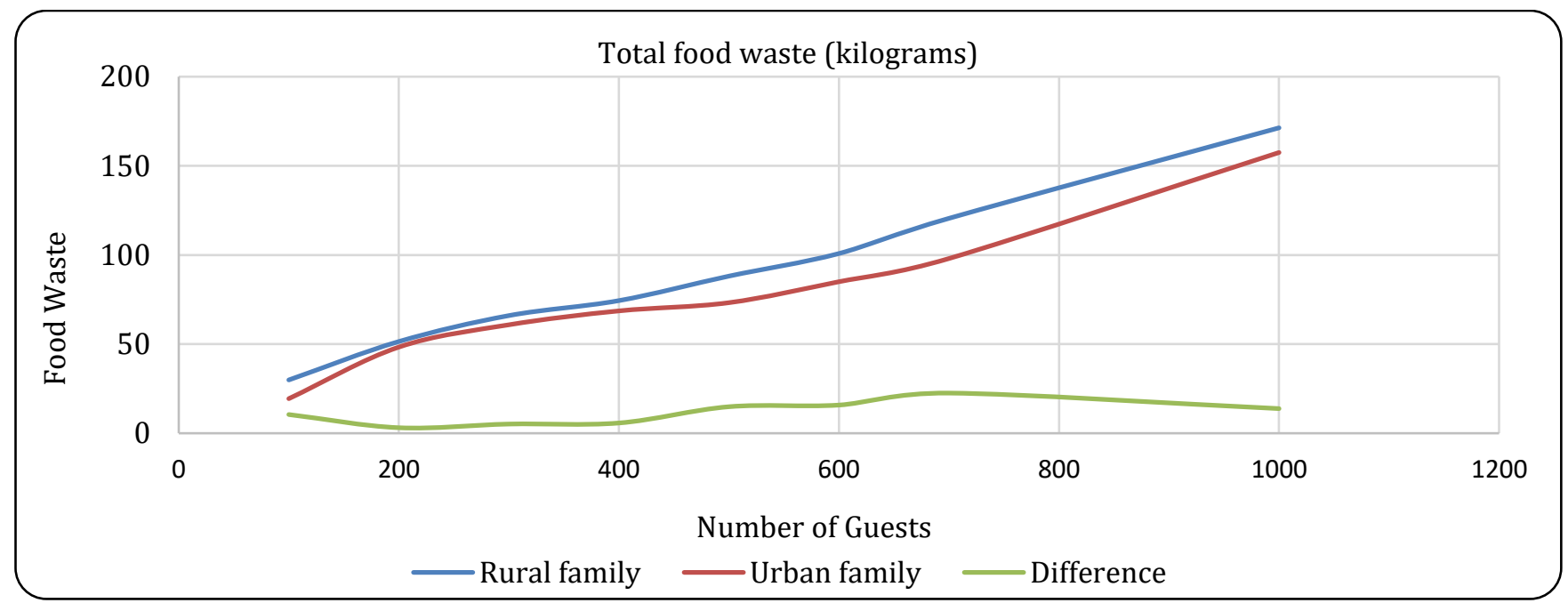

Figure 2. Trend in food waste for rural and urban families.

Table 4. Cross tabulation of number of guests and type of serving (kilograms).

\begin{tabular}{lccc}
\hline No. of Guests & Buffet & On-table serving & Difference \\
\hline $0-100$ & 28.800 & 21.600 & 7.200 \\
$101-200$ & 55.900 & 38.800 & 17.100 \\
$201-300$ & 70.150 & 51.500 & 18.650 \\
$301-400$ & 81.150 & 55.400 & 25.750 \\
$401-500$ & 92.433 & 58.667 & 33.766 \\
$501-600$ & 104.700 & 70.900 & 33.800 \\
$601-700$ & 126.650 & 79.000 & 47.650 \\
$701-1000$ & 199.450 & 97.000 & 102.450
\end{tabular}

Source: Author's estimation from survey data

The total quantity food waste for buffet and on-table serving events is given in Table 4. It provides the total quantity of food waste classified for number of guests in buffet serving and in on-table serving events. The quantity of food waste is significantly high in buffet serving for all the events (classified on the basis of number of invited guests) as compared to on-table serving. Figure 3 clearly shows that the difference in the quantity of food waste for buffet serving and on-table serving increases with the increase in the number of invited guests. Just for the comparison, the results in table show that a buffet serving event with the number of invited guests $301-400$ produces 25 kilograms more food waste than an on-table serving event. For the slab of 701-1000 invited guests, this difference approaches to more than 100 kilograms. 


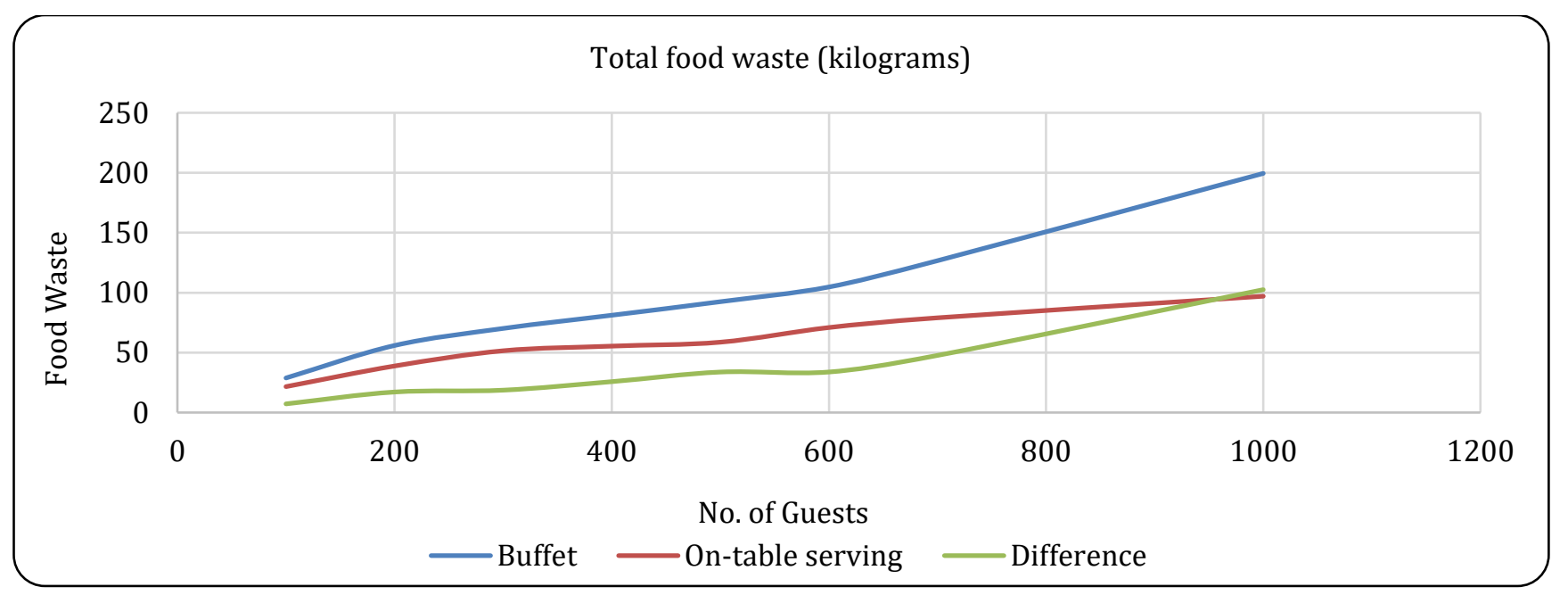

Figure 3. Trend in food waste for buffet and on-table serving.

Table 5. Cross tabulation of number of guests and type of dishes (kilograms).

\begin{tabular}{lcccc}
\hline No. of Guests & Beef & Chicken & Mutton & Difference (Chicken-Mutton) \\
\hline $0-100$ & 21.667 & 29.900 & 16.000 & 13.900 \\
$101-200$ & 44.750 & 54.778 & 40.500 & 14.278 \\
$201-300$ & 59.125 & 68.278 & 54.000 & 14.278 \\
$301-400$ & 69.067 & 76.079 & 61.000 & 15.079 \\
$401-500$ & 79.545 & 85.828 & 57.800 & 28.028 \\
$501-600$ & 86.222 & 102.000 & 73.250 & 28.750 \\
$601-700$ & 116.500 & 114.059 & 90.400 & 23.659 \\
$701-1000$ & 167.444 & 182.154 & 135.500 & 46.654 \\
\hline
\end{tabular}

Source: Author's estimation from survey data

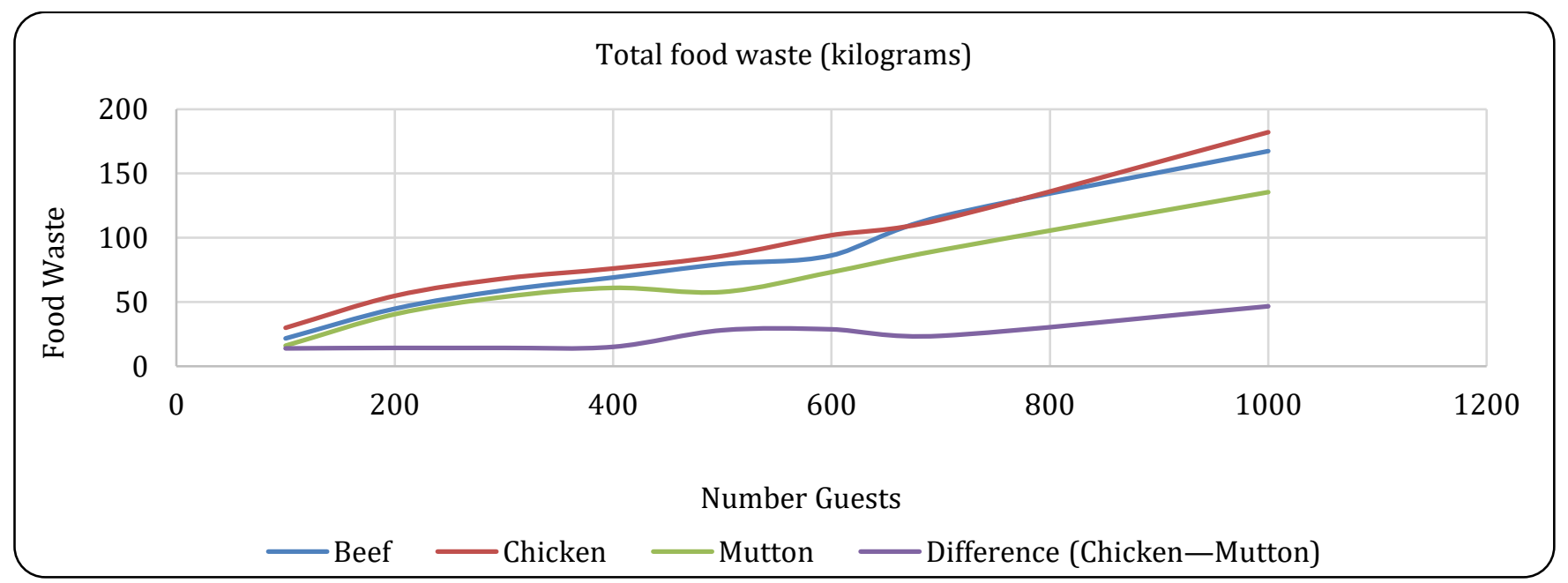

Figure 4. Trend in food waste for beef, chicken and mutton dishes.

Table 5 provide the results of total quantity of food waste for the events with different type of dishes classified for number of invited guests. The results show that the events in which dish-type "chicken" was served have the highest quantity of food waste as compared to the events in which beef or mutton is served. The events with the dish-type "mutton" have the least quantity of food waste among all. The table also presents the results 
of the difference in the food waste of events served with chicken and events served with mutton. The results on the difference show that a chicken-serving event with $401-500$ invited guests produces almost 28 kilogram more food waste as compared to a mutton-serving event. Similarly, for the slab of 701-1000 guest's event, the difference in the food waste approaches to 46 kilograms. Figure 4 shows the increasing trend in the quantity of food waste with the increase in the number of invited guests. It also shows that the difference in the quantity of food waste is larger for higher number of invited guests and smaller for lower number of invited guests.

Table 6. per person food waste classified as number of guests and family background (grams).

\begin{tabular}{lccc}
\hline No. of Guests & Rural family & Urban family & Difference \\
\hline $0-100$ & 299 & 194 & 105 \\
$101-200$ & 257 & 242 & 15 \\
$201-300$ & 220 & 203 & 17 \\
$301-400$ & 186 & 172 & 14 \\
$401-500$ & 176 & 146 & 30 \\
$501-600$ & 168 & 142 & 26 \\
$601-700$ & 172 & 140 & 32 \\
$701-1000$ & 171 & 157 & 14 \\
\hline
\end{tabular}

Source: Author's estimation from survey data

Table 6 shows the quantity of per person food waste for families with different backgrounds (rural or urban). The results show that per person food waste is higher in the events arranged for rural families as compare to urban families. The highest difference in the per person food waste for the rural and urban families is for the slab of $0-100$ guests. This difference is more the 100 grams per person. The second-highest difference in the per person food waste is for the slab of $601-700$ guests.

Figure 5 also shows that the per person food waste is higher in rural families as compare to urban families. It also shows that the per person food waste has declining trend with the increase in number of invited guests in both rural and urban family cases.
Table 7 provides the results of the per person food waste in buffet serving events and in on-table serving events. The results show that per person food waste is higher in events organized with buffet serving as compare to the events with on-table serving.

It is apparent from figure 6 that per person waste in buffet serving and in on-table serving decreases as number of invited guests increases. The highest difference in the per person food waste is 102 grams that is for the slab of events with invited guests between 701-1000. Another significant difference exists for the slab of $101-200$ guests that is 86 grams more in events with buffet serving as compare to on-table serving events.

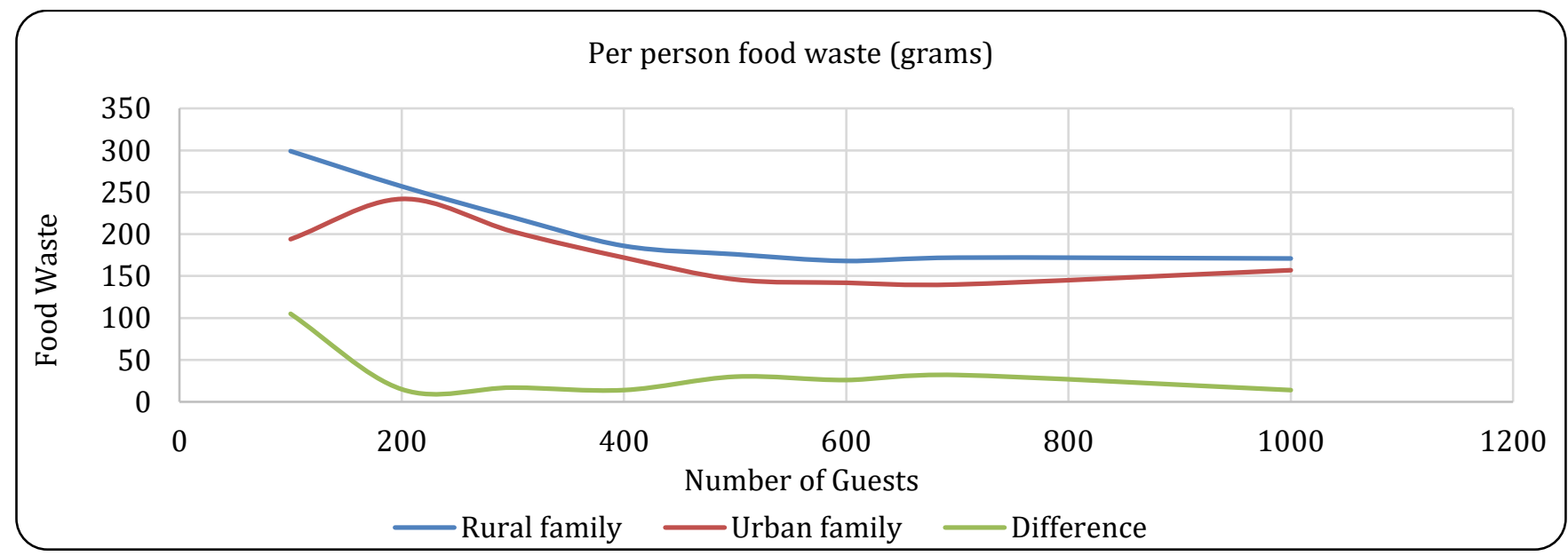

Figure 5. Trend in per person food waste of rural and urban families. 
Table 7. Per person food waste classified as number of guests and type of serving (grams).

\begin{tabular}{lccc}
\hline No. of Guests & Buffet & On-table serving & Difference \\
\hline $0-100$ & 288 & 216 & 72 \\
$101-200$ & 280 & 194 & 86 \\
$201-300$ & 234 & 172 & 62 \\
$301-400$ & 203 & 139 & 64 \\
$401-500$ & 185 & 117 & 68 \\
$501-600$ & 175 & 118 & 57 \\
$601-700$ & 181 & 113 & 68 \\
$701-1000$ & 199 & 97 & 102 \\
\hline
\end{tabular}

Per person food waste (grams)

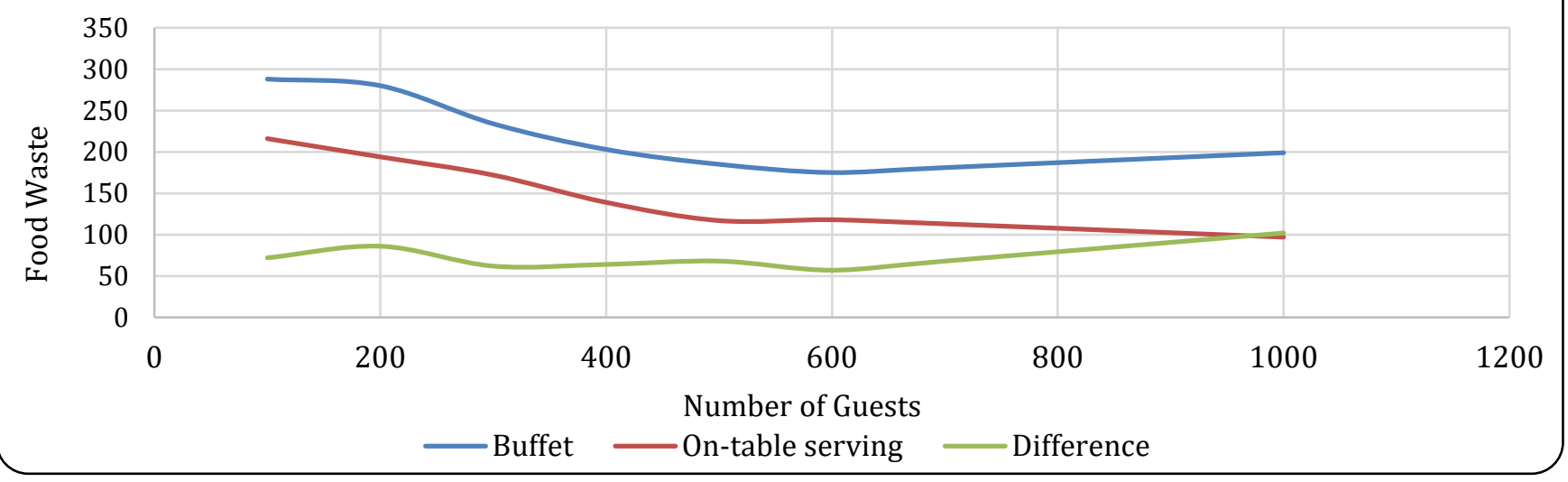

Figure 6. Trend in per person food waste of buffet and on-table serving.

Table 8. per person food waste classified as number of guests and type of dishes (grams).

\begin{tabular}{lcccc}
\hline No. of Guests & Beef & Chicken & Mutton & Difference (Chicken-Mutton) \\
\hline $0-100$ & 217 & 299 & 160 & 139 \\
$101-200$ & 224 & 274 & 203 & 71 \\
$201-300$ & 197 & 228 & 180 & 48 \\
$301-400$ & 173 & 190 & 153 & 37 \\
$401-500$ & 159 & 172 & 116 & 48 \\
$501-600$ & 144 & 170 & 122 & 34 \\
$601-700$ & 166 & 163 & 129 & 47 \\
$701-1000$ & 167 & 182 & 135 & \\
\hline
\end{tabular}

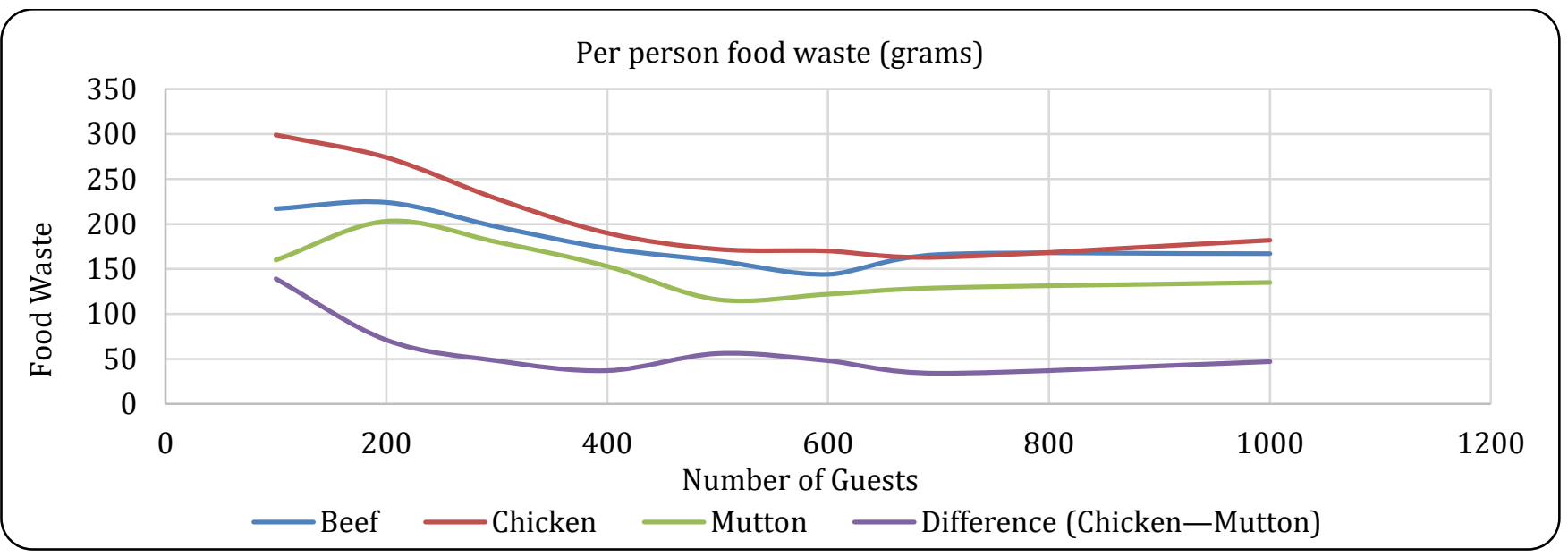

Figure 7. Trend in per person food waste of beef, chicken and mutton dishes. 
Table 8 provides the classification of per person food waste according to the type of dishes and number of guests. The results show that per person food waste is highest in the events served with chicken dish and the smallest in the events served with mutton dish. Though per person food waste is in the least quantity in the events served with mutton, yet the quantity of per person food waste is 115 grams and touches a maximum of 203 grams. Similarly, in the events served with chicken, the quantity of per person food waste lies between a minimum of 163 grams to a maximum of 299 grams. The case for the beef events is not so different where per person food waste ranges from a minimum of 144 grams to a maximum of 224 grams. Figure 7 shows that per person food waste decreases as number of invited guest increases. The difference of the chickenmutton food waste also decreases as number of invited guests increases. As it was established on the basis of interviews and focus group discussions that human behavior is one of the major causes of food waste. This result is consistent with the studies of (Graham-Rowe et al., 2014; Janssens et al., 2019; Quested et al., 2013). The per person quantity of food waste is much less than the estimation of (Farooqi et al., 2016). However, some reasons of food waste such as scrambling around food table, inappropriate food combination and guests unawareness about food waste are common with Farooqi et al. (2016).

\section{CONCLUSION AND RECOMMENDATIONS}

Food waste is clearly a complex issue with a multitude of factors impacting food waste. The aim of the study was to estimate the quantity of food waste and to identify the reasons of this waste in district Sargodha. The study concludes that, on average, every individual waste 183 grams of food in a marriage ceremony in district Sargodha. From theoretical side, it is concluded that guest's unawareness about food waste and the typical behaviour of the guests are the major reasons of food waste in marriage ceremonies. While on the empirical side, the major reason of food waste is the buffet serving that causes to increase the quantity of food waste very significantly. The rural background of the families invited in the events also contribute more towards food waste as compare to urban families. Similarly, events served with chicken have higher quantity of food waste as compare to the events served either with beef or mutton. Per person food waste is higher in the events with smaller number of invited guests and lower in the events with higher number of invited guests. It has decreasing trend with the increase in number of invited guests.

The awareness about food waste can be an important element in controlling food waste. It is recommended that awareness campaign regarding food waste should be launched. Because people from rural background waste more quantity of food per person as compare to urban people so the people from rural background should be targeted in this regard. Buffet serving also causes to increase the quantity of food waste in marriage ceremonies It is also recommended to make it mandatory for the administration of marriage halls to serve the food on the tables. The human behaviour plays a key role to avoid food waste in the marriage ceremonies. To realize the importance of food to the people, the district governments should bound the marriage halls administration to display boards and flexes with information about the food waste and its effects on the environment. This will be helpful in changing the behaviour of the people of wasting food.

\section{ACKNOWLEDGEMENTS}

This study was funded by Higher Education Commission of Pakistan under NRPU project: 9613. We would like thank Mr. Javed Iqbal from Sargodha Chamber of Commerce and Industry for his helpful advice and support during the study.

\section{REFERENCES}

Aamir, M., H. Ahmad, Q. Javaid and S. M. Hasan. 2018. Waste Not, Want Not: A Case Study on Food Waste in Restaurants of Lahore, Pakistan. Journal of Food Products Marketing, 24: 591-610.

Ajzen, I. 1991. The theory of planned behavior. Organizational Behavior and Human Decision Processes, 50: 179-211.

Black, R. E., C. G. Victora, S. P. Walker, Z. A. Bhutta, P. Christian, M. de Onis, M. Ezzati, S. GranthamMcGregor, J. Katz, R. Martorell and R. Uauy. 2013. Maternal and child undernutrition and overweight in low-income and middle-income countries. The Lancet, 382: 427-51.

Block, L. G., P. A. Keller, B. Vallen, S. Williamson, M. M. Birau, A. Grinstein, K. L. Haws, M. C. LaBarge, C. Lamberton, E. S. Moore, E. M. Moscato, R. W. Reczek and A. H. Tangari. 2016. The Squander 
Sequence: Understanding Food Waste at Each Stage of the Consumer Decision-Making Process. Journal of Public Policy \& Marketing, 35: 292-304.

Bravi, L., F. Murmura, E. Savelli and E. Viganò. 2019. Motivations and Actions to Prevent Food Waste among Young Italian Consumers. Sustainability, 11: 1110.

Calvo-Porral, C., A. F. Medín and C. Losada-López. 2016. Can Marketing Help in Tackling Food Waste?: Proposals in Developed Countries. Journal of Food Products Marketing, 23: 42-60.

Cuéllar, A. D. and M. E. Webber. 2010. Wasted food, wasted energy: the embedded energy in food waste in the United States. Environmental science \& technology, 44: 6464-69.

Falasconi, L., M. Vittuari, A. Politano and A. Segrè. 2015. Food Waste in School Catering: An Italian Case Study. Sustainability, 7: 14745-60.

FAO. 2011. Global food losses and food waste-Extent, causes and prevention.

Farooqi, A., A. Ahmed and M. F. Yaseen. 2016. Worldwide Food Waste in Muslim Marriage Ceremonies: A Case Study Conducted in Karachi, A Mega City Of 23.5 Million, And City of Diverse Muslim Communities. International Journal of Business, Economics and Law, 10: 61-72.

Godfray, H. C. J., J. R. Beddington, I. R. Crute, L. Haddad, D. Lawrence, J. F. Muir, J. Pretty, S. Robinson, S. M. Thomas and C. Toulmin. 2010. Food Security: The Challenge of Feeding 9 Billion People. Science, 327: 812-18.

Graham-Rowe, E., D. C. Jessop and P. Sparks. 2014. Identifying motivations and barriers to minimising household food waste. Resources, Conservation and Recycling, 84: 15-23.

Gustavsson, J., Cederberg, C., Sonesson, U., Van Otterdijk, R., \& Meybeck, A. 2011. Global Food Sosses and Food Waste--Extent, Causes and Prevention. FAO Rome, Italy.

Hiç, C., P. Pradhan, D. Rybski and J. P. Kropp. 2016. Food Surplus and Its Climate Burdens. Environmental Science \& Technology, 50: 4269-77.

Janssen, A. M., M. A. Nijenhuis-de Vries, E. P. J. Boer and S. Kremer. 2017. Fresh, frozen, or ambient food equivalents and their impact on food waste generation in Dutch households. Waste Management, 67: 298-307.

Janssens, K., W. Lambrechts, A. van Osch and J. Semeijn.
2019. How Consumer Behavior in Daily Food Provisioning Affects Food Waste at Household Level in The Netherlands. Foods (Basel, Switzerland), 8: 428.

Kummu, M., H. de Moel, M. Porkka, S. Siebert, O. Varis and P. J. Ward. 2012. Lost food, wasted resources: Global food supply chain losses and their impacts on freshwater, cropland, and fertiliser use. Science of The Total Environment, 438: 477-89.

Mabaso, C. H. and D. Hewson. 2018. Employees' perceptions of food waste management in hotels. African Journal of Hospitality, Tourism and Leisure, 7: 1-15.

Papargyropoulou, E., R. Lozano, J. K. Steinberger, N. Wright and Z. b. Ujang. 2014. The food waste hierarchy as a framework for the management of food surplus and food waste. Journal of Cleaner Production, 76: 106-15.

Quested, T. E., E. Marsh, D. Stunell and A. D. Parry. 2013. Spaghetti soup: The complex world of food waste behaviours. Resources, Conservation and Recycling, 79: 43-51.

Quested, T. E., A. D. Parry, S. Easteal and R. Swannell. 2011. Food and drink waste from households in the UK. Nutrition Bulletin, 36: 460-67.

Roodhuyzen, D. M. A., P. A. Luning, V. Fogliano and L. P. A. Steenbekkers. 2017. Putting together the puzzle of consumer food waste: Towards an integral perspective. Trends in Food Science \& Technology, 68: 37-50.

Schanes, K., K. Dobernig and B. Gözet. 2018. Food waste matters - A systematic review of household food waste practices and their policy implications. Journal of Cleaner Production, 182: 978-91.

Schanes, K., S. Giljum and E. Hertwich. 2016. Low carbon lifestyles: A framework to structure consumption strategies and options to reduce carbon footprints. Journal of Cleaner Production, 139: 1033-43.

Searchinger, T., R. Waite, C. Hanson, J. Ranganathan, P. Dumas, E. Matthews and C. Klirs. 2019. Creating a sustainable food future: A menu of solutions to feed nearly 10 billion people by 2050 . Final report WRI.

Strotmann, C., S. Friedrich, J. Kreyenschmidt, P. Teitscheid and G. Ritter. 2017. Comparing Food Provided and Wasted before and after Implementing Measures against Food Waste in Three Healthcare Food Service Facilities. 
Sustainability, 9: 1409.

Thyberg, K. L. and D. J. Tonjes. 2016. Drivers of food waste and their implications for sustainable policy development. Resources, Conservation and Recycling, 106: 110-23.

Vittuari, M., F. De Menna and M. Pagani. 2016. The
Hidden Burden of Food Waste: The Double Energy Waste in Italy. Energies, 9: 660.

Wilkie, A., R. Graunke and C. Cornejo. 2015. Food Waste Auditing at Three Florida Schools. Sustainability, 7: 1370-87.

Publisher's note: EScience Press remains neutral with regard to jurisdictional claims in published maps and institutional affiliations.

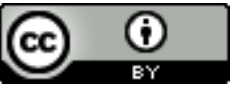

Open Access This article is licensed under a Creative Commons Attribution 4.0 International License, which permits use, sharing, adaptation, distribution and reproduction in any medium or format, as long as you give appropriate credit to the original author(s) and the source, provide a link to the Creative Commons license and indicate if changes were made. The images or other third-party material in this article are included in the article's Creative Commons license, unless indicated otherwise in a credit line to the material. If material is not included in the article's Creative Commons license and your intended use is not permitted by statutory regulation or exceeds the permitted use, you will need to obtain permission directly from the copyright holder. To view a copy of this license, visit http://creativecommons.org/licenses/by/4.0/. 